\title{
An Extended Event Tree Risk Analysis Under Fuzzy Logic Environment: The Case of Fire in Ship Engine Room
}

\author{
(1) Ahmet Lutfi Tuncel, ๑ Emre Akyuz, @ (1) Ozcan Arslan
}

İstanbul Technical University, Maritime Faculty, Department of Maritime Transportation and Management Engineering, İstanbul, Turkey

\begin{abstract}
Ship engine room fire is one of the major dangers that threaten the safety of the ships. An effective firefighting in the engine room is critical to prevent possible destructive consequences on-board ship. Fire detection and firefighting systems, which are designed for an effective fire prevention on-board ship, need to work flawlessly. In order to achieve this, the deficiencies of the designed systems must be determined and necessary control actions must be taken. In this study, failure probabilities of fire detection and firefighting systems on-board ship is calculated by event tree analysis and fuzzy logic environment. The possible consequences that may be encountered in case the systems fail under various scenarios are determined. Solutions have been proposed in order to minimize the risk that may arise by reducing the failure probability of each system. The outcome of this paper will be utilised by safety engineers, shipping companies and safety inspectors to prevent potential engine room fires.
\end{abstract}

Keywords

Risk analysis, Event tree, Fuzzy logic, Engine room fire

\section{Introduction}

Ship fires may cause great financial losses as well as loss of life, property and environmental pollution. These fires, which may have devastating outcomes, are among the most dangerous of maritime accidents [1-3]. There is also a common view that ship fires are among the most frequent accidents $[2,4,5]$. Although navigation safety has increased a considerable amount with the fire prevention systems installed on ships, large-scale ship fires continue to occur [6]. In this respect, an effective firefighting system is significant with regard to reducing the destruction caused by fires.

In efforts to control ship fires, the compartment in which the fire has started is of great importance, in addition to the type and the size of the fire. One of the compartments of ships in which fires frequently occur is the engine room. Upon an examination of fires that occurred on 165 ships between 1992 and 1997, it was concluded that approximately twothirds of those fires had started in engine rooms [7]. In addition, engine rooms are the most important sections of ships regarding both the generation of power and electricity and the critical equipment they contain [8-10]. In this respect, engine room fires may also cause various other related accidents, such as collisions or groundings following a blackout [11].

Fire detection and fighting systems have been designed to control ship fires in a short time to reduce the destruction that ship fires cause. The construction properties and requirements of these systems are determined under the International Convention for the Safety of Life at Sea (SOLAS 74), Chapter II-2 [12]. In addition, the technical and engineering requirements of these systems are elaborated in the International Code for Fire Safety Systems (FSS Code) [13]. Firefighting systems used on ships may exhibit differences regarding the specific properties of the ships in accordance with the provisions of SOLAS 74.

It is of great importance to determine to what extent the fire detection and firefighting systems are ready against fires

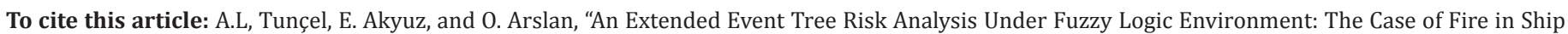
Engine Room." Journal of ETA Maritime Science, vol. 9(3), pp. 210-220, 2021.

${ }^{C}$ Copyright 2021 by the Journal of ETA Maritime Science published by UCTEA Chamber of Marine Engineers 
that may occur in the engine room of the ships. In this study, it is aimed to determine the probability of failure of the existing fire detection and fire extinguishing systems during a possible fire response in the engine rooms of the ships.

In this context, a model created using fuzzy logic and event tree analysis (ETA) methods was applied and the failure probabilities of these systems were calculated. In addition, possible consequences that may be encountered as a result of the systems failure were determined and thus a comprehensive quantitative risk analysis was performed. The paper is organised as follows. Section 1 gives brief definition about fire safety and firefighting system on-board ship. Section 2 summarises literature reviewing about fire safety on-board ships. Section 3 introduces methodologies. Section 4 performs empirical risk analysis for firefighting systems in engine rooms. Section 5 evaluates the outputs of the risk analysis. Section 6 concludes the research and advise further studies.

\section{Literature Review}

The literature contains many risk analysis studies on ship fires. For instance, Puisa et al. [11] examined the causes of accidents resulting in engine room fires in modern ships using the Causal Analysis Based on STAMP method, taking a real cruise ship fire as a case study. Uğurlu [14] analyzed the root causes and causal factors leading fires and explosions in tanker vessels carrying hazardous liquid cargo using a model that created with fault tree analysis (FTA), Monte Carlo simulation and the fuzzy extended analytical hierarchy process (AHP). Similarly, Guan et al. [15] revealed the root causes that lead to fire and explosion accidents in engine rooms of dual-fuel ships navigating in Chinese internal waters, using FTA. Karahalios [16] examined 77 accident reports and investigated the dangers of engine room fires using the AHP. In the study, it was also emphasised the significance of the Master's coping with the factor of stress in deciding to firefighting. In another study, Baalisampang et al. [3] investigated the causes of fire and explosion accidents occurred in the maritime sector between 1990 and 2015 . The study also focused on the effect of alternative fuels on the elimination of accident causes [3].

It has been emphasised that human errors are the primary elements that cause marine accidents, in many studies in the literature [17-20]. In this respect, there are also studies specifically investigating the effect of human factors on the occurrence of ship fires. For example, Sarıalioğlu et al. [8] investigated the root causes leading fire and explosion accidents that occurred between 2000 and 2017 in the engine rooms of ships of 500 GRT using fuzzy FTA and Human Factors Analysis and Classification System (HFACS) methods. Schröder-Hinrichs et al. [21] examined 41 fire and explosion accident reports that occurred in the engine rooms of the ships and revealed the reasons of the accident with the model created as a result of minor modifications in the HFACS method. Soner et al. [22] analyzed the root causes of deficiencies linked to ship fires using a model that created with the fuzzy cognitive mapping and HFACS methods.

There are also studies investigating ship fires using various software and simulation techniques. Among these, Sarvari et al. [23] provided solutions for safe evacuation of passengers from fast ferries in the case of fire in ship engine room, using various simulations. In addition, Su and Wang [9] investigated fire formation and development processes in multi-layer structured engine rooms, using 3D modelling software.

There are also studies in the literature that address the effect of training in preventing ship fires. For instance, Tac et al. [24] measured the effectiveness of firefighting drills on an oil/product ship using fuzzy decision-making trial and evaluation laboratory method. Also, Tao et al. [25] emphasised the significance of simulation techniques in their studies investigating the most efficient and the least costly training to be provided to a ship's crew about firefighting.

Studies investigating the effects of present risk analysis approaches on preventing potential fires also stand out. Among these, McNay et al. [26] investigated the most efficient approaches in providing prevention of fire accidents in ship engine rooms by analysing accident research methods and current regulations such as formal safety assessment. Jin and Jang [27] stated that current fire risk assessment (FRA) analyses are not sufficient for the structural safety of offshore platforms against fire accidents and they provided a new risk analysis approach. Yang et al. [28] asserted that floating liquefied natural gas (LNG) offshore platforms contain numerous hazardous elements that may cause fires and they analysed how reliable fire safety measures were for these platforms using computational fluid dynamics code.

When the studies on ship fires in the literature are examined in detail, it is seen that most of them investigate the causes of fire accidents and offers solutions to prevent the occurrence of such accidents [3,8,11,14-16,21,22]. In this study, the probabilities of failure of fire detection and extinguishing systems used in the fight against an engine room fire were investigated. In this context, it is aimed to identify the system with the highest probability of failure. In addition, the results of various levels of risks that may be encountered as a result of the failure of the designed fire extinguishing systems have been investigated. In this respect, it is distinguished from other studies in the 
literature. The study is important in terms of determining the failure levels of the systems used during the fight against engine room fires and presenting what kind of measures should be taken in order to improve the systems with a high probability of failure. In addition, various levels of risks that may be encountered after a possible engine room fire have been digitized with a model created from fuzzy logic and ETA methods. In the study, an approach was obtained that will allow the risk levels to be evaluated both quantitatively and qualitatively, in this regard it is thought that it will contribute to the literature.

\section{Materials and Methodology}

In this study, a quantitative risk analysis was conducted on fire detection and firefighting systems used to control engine room fires with the application of the model created with fuzzy logic and ETA methods. The steps in the implementation of these methods are elaborated in the following sections.

\subsection{Fuzzy Sets}

Fuzzy set theory is an approach developed as a result of the insufficiency of conventional probability methodologies in explaining the ambiguities in decision-making processes [29]. This method enables the obtaining of linguistic expressions by referring to expert opinions [30]. The linguistic expressions obtained from expert opinions are subsequently converted into numerical values. Zadeh [29] explained that a fuzzy subset $A$ in X can be demostrated by a membership function $\mu_{A}(x)$, which is associated with each element $\mathrm{x}$ in X (a crisp set which is a collection of elements or objects) via a real number between 0 and 1 .

Additionally, membership functions can take different types of shapes, with triangular and trapezoidal being the most commonly used membership functions [31,32]. In this study, trapezoidal membership functions were used. Equation (1) gives the trapezoidal fuzzy set of numbers labelled $(a, b, c$, d) [33].

$$
\mu_{A}(x)=\left\{\begin{array}{l}
\frac{x-a}{b-a}, a \leq x \leq b \\
1, \quad b \leq x \leq c \\
\frac{d-x}{d-c}, \quad c \leq x \leq d \quad, \quad a<b<c<d \\
0, \quad \text { or else }
\end{array}\right.
$$

\subsection{ETA}

ETA is an inductive risk analysis method that enables both qualitative and quantitative evaluations [34]. The analysis process of ETA starts with the occurrence of a specific initiating event (IE). This analytical technique also provides the possibility of a bottom-up approach and enables the investigation of various scenarios (i.e., event sequences) that may occur following the IE [35]. In other words, ETA shows the logical combination of different events that may be encountered after the IE [36]. ETA divides the findings into new paths depending on whether the designed barriers fail or not and allows us to predict the outcomes we may encounter after each process $[37,38]$. In addition, it provides quantitative evaluation by calculating the probability values of the each outcome that may be encountered [35]. In this respect, it enables us to test how functional the designated barriers are. ETA has a wide area of implementation in safety engineering in addition to nuclear and chemical safety $[37,38]$. There are also risk analysis studies using ETA in the maritime field $[39,40]$. For instance, Fu et al. [39] analyzed the potential risks that could be encountered in the event of a possible LNG leakage on LNG-fueled ships by utilizing ETA. In another study, Raiyan et al. [40] analyzed various types of maritime accidents in Bangladesh waters using the ETA.

The concept of barrier or safety barrier has varying definitions in the literature. While Duijm [41] defined this concept as the rules, equipment and structural tools that would prevent the occurrence of an accident, Sklet [42] interpreted it as all instruments, physical and non-physical, to prevent undesired events or incidents or to reduce their severity. In addition, Rausand [43] categorised safety barriers into two groups as primary and secondary barriers. In this respect, the barriers designed in accordance with ETA can be argued to be types of mitigation barriers to minimise the level of risk that may arise as a result of an accident. Safety barrier analyses, on the other hand, enable the determination of how efficient the designed safety systems are and the detection of deficiencies [44].

\subsection{ETA in Fuzzy Environments: Integrated Methodology \\ In this section, the model created as a result of the integration of fuzzy logic and ETA methods are explained.}

\subsubsection{Constructing the Event Tree (ET) Diagram}

First, the IE was determined. The IE was considered as fire accidents occurring after an explosion in ship engine rooms. Thereafter, appropriate mitigation barriers to overcome fire accidents in ship engine rooms with the least damage were selected and the ET diagram was drawn.

\subsubsection{Calculation of Possibilities from Expert Judgements}

Since there are not sufficient data available to conduct risk analysis on specific issues in the maritime sector, the 
use of expert opinions provides practical solutions [45]. Experts with different levels of knowledge, experience and training were asked about the probabilities of the failure of each mitigation barrier defined in this study. Regarding this topic, Yuhua and Datao [46] developed a weighting score for obtaining the most efficient evaluation from experts with different backgrounds. Akyuz et al. [47] defined such experts as heterogeneous expert groups. In addition, Hsu and Chen [48] introduced an approach known as the similarity aggregation method (SAM), which can convert linguistic evaluations obtained from a non-uniform group of experts into relevant fuzzy numbers. The implementation phases of the SAM are explained below.

\section{Phase 1. Aggregating obtained possibilities}

Let us assume that $E_{u, v}(u, v=1,2,3, . ., m)$ expert opinions from $m$ experts were referred to in this study. Every expert would make evaluations regarding the predetermined linguistic variables. The linguistic evaluations obtained are converted into relevant fuzzy numbers further on in the process. The details of this conversion are presented below [45]:

\section{Step 1. Calculate the degree of agreement}

In the first sub-stage, $E_{u}$ and $E_{v}$ represent each pair of experts. $S_{u}{ }_{v}\left(\widetilde{R}_{u} \widetilde{R}_{u}^{u}\right)$ symbolise expert opinions within the interval $\in[0,1]$. In this regard, both $\bar{A}=\left(a_{1}, a_{2}, a_{3}, a_{4}\right)$ and $\bar{B}=\left(b_{1}, b_{2}, b_{3}, b_{4}\right)$ are generic trapezoidal fuzzy numbers. Similarities between two fuzzy numbers can be calculated with "S", a similarity function [45], as explained in Equation (2).

$S(\tilde{A}, \tilde{B})=1-1 / 4 \sum_{i=1}^{4}\left|a_{i}-b_{i}\right|$

Here, $S(\tilde{A}, \tilde{B}) \in[0,1]$.

\section{Step 2. Compute average agreement (AA) degree} $A A\left(E_{u}\right)$ of the experts

In the second sub-stage, Equation (3) is used to specify the AA degree.

$$
A A\left(E_{u}\right)=\frac{1}{M-1} \sum_{u \neq v}^{M} S\left(\tilde{R}_{u}, \tilde{R}_{v}\right)
$$

\section{Step 3. Determine relative agreement (RA) degree}

\section{$R A\left(E_{u}\right)$ of the experts}

In the third sub-stage, Equation (4) is employed to calculate the RA degree.

$E_{u}(u=1,2,3, \ldots, M)$ as $R A\left(E_{u}\right)=\frac{A\left(E_{u}\right)}{\sum_{u=1}^{M} A\left(E_{u}\right)}$

\section{Step 4. Predict consensus coefficient (CC) degree} $C C\left(E_{u}\right)$ of the experts

In the fourth sub-stage, Equation (5) is utilised to predict the consensus coefficient degree.

$$
\begin{aligned}
& E_{u}:(\mathrm{u}=1,2,3, \ldots, \mathrm{M}) \\
& C C\left(E_{u}\right)=\beta \cdot w\left(E_{u}\right)+(1-\beta) \cdot R A\left(E_{u}\right)
\end{aligned}
$$

Here, $w\left(E_{u}\right)$ represents weighting score of a pair of expert.

\section{Step 5. Aggregate the result of the experts' judgements}

In the final sub-stage of the SAM, Equation (6) is used to aggregate the result of each expert's judgment (AG).

$$
\tilde{R}_{A G}=C C\left(E_{1}\right) \times \tilde{R}_{1}+C C\left(E_{2}\right) \times \tilde{R}_{2}+\ldots+C C\left(E_{M}\right) \times \widetilde{R}_{M}
$$

\section{Phase 2. Defuzzify of the aggregated experts' judgement (fuzzy possibility)}

In this process, the aggregated trapezoidal fuzzy numbers are converted into crisp values. Here, the aim is defuzzifying with a centre of area $(\mathrm{COA})$ technique, as presented in Equation (7) $[45,49]$.

$$
X^{*}=\frac{\int u_{i}(x) x d x}{\int u_{i}(x)}
$$

In this context, $X^{*}$ denotes fuzzy possibility, $u_{i}(X)$ denotes the aggregated membership function and $x$ denotes the output variable.

\section{Phase 3. Turn possibilities into probabilities}

In this process, possibilities obtained as a result of expert judgements are transformed into probability values. With this aim, Onisawa [50] introduced a formula in light of a new approach to convert fuzzy failure possibilities into fuzzy failure probabilities. Fuzzy probabilities $(F P r)$ can be obtained from the fuzzy possibilities ( $F P s)$. In this context, Equations (8) and (9) are used for the calculations. Here, K, as shown in Equation (9), is a constant value that represents safety criteria depending on fault rates or routine fault rates $[47,51]$.

$$
\begin{gathered}
F P r=\left\{\begin{array}{c}
\frac{1}{10^{k}}, F P S \neq 0 \\
0, F P S=0
\end{array}\right. \\
K=\left[\left(\frac{1-F P S}{F P S}\right)\right]^{1 / 3} \times 2.301
\end{gathered}
$$

\subsection{Probability Calculation of Each Outcome}

In this section of the study, calculations of the probabilities for each outcome to be encountered in the constructed ET 
diagram are performed. First, the success probability value was obtained using the calculated failure probability for each designed barrier. The relation between the probability of failure and probability of success is presented in Equation (10) [52].

$P(B 1)+P\left(B 1^{\prime}\right)=1$

Here, as an example, $\mathrm{P}(\mathrm{B} 1)$ is the B1 barrier's failure probability, while $\mathrm{P}\left(\mathrm{B} 1^{\prime}\right)$ is the probability that barrier $\mathrm{B} 1$ will not fail, i.e. probability of success.

Each end point in the ET diagram indicates an outcome to be encountered. The probability of each outcome will be the conditional probability of failure or success for all barriers on the path starting from the IE [35,52]. For instance, the probability of the outcome to be obtained in a scenario in which the B1 barrier fails and the B2 barrier succeeds is presented in Equation (11).

$P(O)=P(I E) \times P(B 1) \times P\left(B 2^{\prime}\right)$

Here, $P(O)$ denotes the probability of the outcome, $P(I E)$ denotes the probability of the IE, $P(B 1)$ denotes the B1 barrier's failure probability and $P\left(B 2^{\prime}\right)$ denotes the probability that the $\mathrm{B} 2$ barrier does not fail.

In this study, the most critical barrier is defined as the barrier with the highest probability of failure among all designed barriers.

\section{Empirical Analysis of Ship Fire Detection and Firefighting Systems}

In this study, a comprehensive risk analysis was conducted to determine the functionality of the designated barriers to fight fires that may occur in the engine rooms of ships of 500 GRT and above.

\subsection{Examined Systems (Designated Barriers)}

In this study, systems used in fighting ship engine room fires are examined within six categories.

\subsubsection{Fire detection and alarm systems}

Early detection of ship fires is of great importance for efficient firefighting and thus for minimising the risks a fire may pose to the crew, the environment and the ship. These systems are designed for the timely detection of potential fires that can be encountered on- board ships. They comprise an alarm panel, fire buttons, fire detectors and several electronic and mechanical parts. Of these parts, the fire detectors are classified into three groups regarding their operational principles. These are flame detectors, smoke detectors and heat detectors [53]. Flame detectors are installed in the compartments with high probabilities of having flaming fires. Smoke detectors enable the early detection of relatively slow-developing fires. Heat detectors operate by sensing the temperature of a heating layer of air [53]. The failure or outage of the fire detection system may prevent the automatic activation of local fixed fire extinguishing systems, which operate synchronously with the system, in addition to the failure in detecting the fire early.

\subsubsection{Water mist systems}

Water mist systems are local fixed fire extinguishing systems that enable the dispersal of water in mist form via nozzles and they can be used to fight potential fires in ship engine rooms. They can be used in places with temperatures higher than those seen in other compartments of the engine room, such as the auxiliary boiler room, auxiliary generators, purifier room and incinerator room. Technically, they can be activated in two ways: automatically and manually. For automatic activation, a fire should be detected by the fire detectors and the fire alarm system should be actively working. Failure of the water mist system may allow fires in critical compartments of the engine room to grow and spread to other compartments.

\subsubsection{Portable fire extinguishers}

Portable fire extinguishers, placed in different compartments of ship engine rooms to fight different types of fires, are designed with different types and capacities. Their types may include carbon dioxide $\left(\mathrm{CO}_{2}\right)$, water, foam and chemical dust. The failure of these fire extinguishers may allow easily controllable fires to grow.

\subsubsection{Fire pumps}

Considering the type and the size of the fire that occurs, sea water may be used as an extinguisher. In such a case, fire pumps are the water pumps that deliver high-pressure sea water to the compartment in which the water will be used via fire lines. The outage of the fire pump or failure in using it may delay the intervention and allow the fire to grow.

\subsubsection{Emergency fire pumps}

In the case of any malfunction in the fire pump, the whole fire line will be out of the loop. In this case, an emergency fire pump may be used alternatively for sea water intake. According to Chapter 12 of the FSS Code, this pump should be activated by a stationary power source that is operated separately [13]. In the case of failure in using this system, the fire may become more devastating.

\subsubsection{Fixed firefighting systems: $\mathrm{CO}_{2}$ flooding systems} $\mathrm{CO}_{2}$ flooding systems are the most common fixed fire systems found in many types of ships. In a potential ship engine room fire, they are used to bring the fire under control by 
dispensing $\mathrm{CO}_{2}$ into the compartment. They are used when a fire cannot be brought under control with portable or other fire extinguishing systems or in line with the directions of the decision-maker depending on the specific conditions of the fire. Technically, these systems comprise many elements such as $\mathrm{CO}_{2}$ bottles, common manifolds, distribution valves, distribution pipe lines and nozzles. In cases in which the fixed firefighting system cannot be operated, the fire may spread throughout the ship and may even devastatingly become incontrollable, in which case the Master would make the decision to abandon the ship.

\subsection{Quantitative Analysis of Ship Engine Room Firefighting Systems}

In this study, SOLAS 74, the FSS Code, the SOLAS Fire Training Manual, FRA and several ship firefighting systems were examined in detail. In addition, a risk analysis of the systems used in fighting potential fires in the engine rooms of ships was performed while referring to marine expert opinions. The IE in this study was determined as a ship engine room fire. Also, six different barriers were determined that could minimise the negative outcomes that fires cause and make it possible to bring fires under control. These are fire detection and alarm system (B1), water mist system (B2), portable fire extinguishers (B3), fire pump (B4), emergency fire pump (B5) and fixed $\mathrm{CO}_{2}$ fire extinguishing system (B6). The probabilities of failure for these designed barriers were calculated and the outcomes were determined in line with different scenarios formed according to the ET diagram. Since there are no statistical data available on the outages, i.e. failures, of the designed barriers, the probabilities of failure for each barrier were obtained by referring to expert opinions. In this study, an expert group comprising 4 chief engineers, 1 academician and 1 electrical engineer was assembled and evaluations were obtained from this group. The ET diagram was also systematically constructed by experts. The profile details of the experts who participated in the study are presented in Table 1.

Different weightings were calculated for the feedback obtained from these experts, since they were not homogeneous in their profiles. This weighting process was conducted using the scales proposed by Lavasani et al. [45] and Kuzu et al. [54]. Weighting scores of the nonhomogeneous experts are presented in Table 2.

The expert opinions obtained in this study were converted to numbers using the fuzzy logic method [55]. The linguistic expressions and trapezoidal fuzzy numbers used in this study are presented in Table 3 [56].

Each maritime expert, all of whom were weighted considering their professional positions, education levels and sea and shore service times, participated in the study
Table 1. Profile details of the maritime experts

\begin{tabular}{|c|c|c|c|c|}
\hline $\begin{array}{c}\text { Maritime } \\
\text { Experts }\end{array}$ & Position & $\begin{array}{c}\text { Maritime } \\
\text { Experience } \\
\text { (Years) }\end{array}$ & $\begin{array}{c}\text { Shore } \\
\text { Service } \\
\text { Time } \\
\text { (Years) }\end{array}$ & $\begin{array}{c}\text { Educational } \\
\text { Level }\end{array}$ \\
\hline 1 & $\begin{array}{c}\text { Chief } \\
\text { Engineer }\end{array}$ & 20 & 4 & BSc \\
\hline 2 & $\begin{array}{c}\text { Chief } \\
\text { Engineer }\end{array}$ & 13 & 9 & BSc \\
\hline 3 & $\begin{array}{c}\text { Chief } \\
\text { Engineer }\end{array}$ & 12 & 5 & BSc \\
\hline 4 & $\begin{array}{c}\text { Chief } \\
\text { Engineer }\end{array}$ & 9 & 2 & MSc \\
\hline 5 & Academician & 4 & 10 & PhD \\
\hline 6 & $\begin{array}{c}\text { Electrical } \\
\text { Engineer }\end{array}$ & 15 & 3 & MSc \\
\hline
\end{tabular}

Table 2. Weighting scores of non-homogenous experts

\begin{tabular}{|c|c|c|}
\hline Group & Classification & Score \\
\hline $\begin{array}{l}\text { Professional position } \\
\qquad\left(\mathrm{a}_{1}\right)\end{array}$ & $\begin{array}{c}\text { Master/Chief engineer } \\
\text { Pilot } \\
\text { Academician } \\
\text { Chief officer } \\
\text { Junior officer/Electrical engineer }\end{array}$ & $\begin{array}{l}5 \\
4 \\
3 \\
2 \\
1\end{array}$ \\
\hline $\begin{array}{l}\text { Sea service time } \\
\qquad\left(a_{2}\right)\end{array}$ & $\begin{array}{c}\geq 16 \text { years } \\
11-15 \\
6-10 \\
3-5 \\
\leq 2\end{array}$ & $\begin{array}{l}5 \\
4 \\
3 \\
2 \\
1\end{array}$ \\
\hline $\begin{array}{l}\text { Shore service time } \\
\qquad\left(a_{3}\right)\end{array}$ & $\begin{array}{c}\geq 20 \text { years } \\
15-19 \\
10-14 \\
6-9 \\
\leq 5\end{array}$ & $\begin{array}{l}5 \\
4 \\
3 \\
2 \\
1\end{array}$ \\
\hline $\begin{array}{l}\text { Education level } \\
\qquad\left(\mathrm{a}_{4}\right)\end{array}$ & $\begin{array}{c}\text { PhD } \\
\text { Master } \\
\text { Bachelor } \\
\text { Higher national diploma } \\
\text { School level }\end{array}$ & $\begin{array}{l}5 \\
4 \\
3 \\
2 \\
1\end{array}$ \\
\hline
\end{tabular}

Table 3. Linguistic terms with trapezoidal fuzzy numbers

\begin{tabular}{|c|c|}
\hline Linguistic terms & Fuzzy numbers \\
\hline Very low (VL) & $(0.0,0.0,0.1,0.2)$ \\
\hline Low (L) & $(0.1,0.2,0.2,0.3)$ \\
\hline Medium low (ML) & $(0.2,0.3,0.4,0.5)$ \\
\hline Medium (M) & $(0.4,0.5,0.5,0.6)$ \\
\hline Medium high (MH) & $(0.5,0.6,0.7,0.8)$ \\
\hline High (H) & $(0.7,0.8,0.8,0.9)$ \\
\hline Very high (VH) & $(0.8,0.9,1.0,1.0)$ \\
\hline
\end{tabular}


at different levels. The weights of each expert profile are presented in Table 4. Linguistic evaluations obtained from the experts for each designed barrier are presented in Table 5.

After obtaining the evaluations of the maritime experts for each designed barrier, the aggregation stage was completed using Equations (2-5). In this context, the similarity functions and similarity values calculated for B1 are presented in Table 6. In addition, the average agreement of the maritime experts (AA), RA of the maritime experts and consensus coefficient (CC) values calculated for B1 are presented in Table 7. Since all experts in this case are maritime experts, the $\beta$ value is taken as 0.5 in the calculations [57]. Later, in order to obtain the aggregated expert judgement values for each failure of barriers built for fighting ship engine room fires, Equation (6) was used. Following these calculations, fuzzy numbers were converted to crisp values using Equation (7) and the defuzzification process was completed. The aggregated expert judgements and the defuzzified failure possibilities of the six barriers in this study are presented in Table 8.

The possibilities pertaining to the barriers obtained from expert evaluations were converted to probabilities to calculate the probability values for each outcome constructed in line with the ET diagram. This conversion was done using Equations (8-9). After that, the probability calculation stage for seven different outcomes determined

Table 4. Weights of the maritime experts

\begin{tabular}{|c|c|c|c|c|c|c|}
\hline $\begin{array}{c}\text { Maritime } \\
\text { expert no }\end{array}$ & \multicolumn{4}{|c|}{ Weighting factor } & $\begin{array}{c}\text { Total } \\
\text { weight }\end{array}$ & $\begin{array}{c}\text { Weighting } \\
\text { score }\end{array}$ \\
\hline 1 & 5 & 5 & 1 & 3 & 14 & 0.18 \\
\hline 2 & 5 & 4 & 2 & 3 & 14 & 0.18 \\
\hline 3 & 5 & 4 & 1 & 3 & 13 & 0.17 \\
\hline 4 & 5 & 3 & 1 & 4 & 13 & 0.17 \\
\hline 5 & 3 & 2 & 3 & 5 & 13 & 0.17 \\
\hline 6 & 1 & 4 & 1 & 4 & 10 & 0.13 \\
\hline
\end{tabular}

Table 5. Linguistic evaluations of the maritime experts for priorities of each barrier

\begin{tabular}{|c|c|c|c|c|c|c|}
\hline $\begin{array}{c}\text { Barriers } \\
\text { (B) }\end{array}$ & $\begin{array}{c}\text { M. Exp } \\
\mathbf{1}\end{array}$ & $\begin{array}{c}\text { M. Exp } \\
\mathbf{2}\end{array}$ & $\begin{array}{c}\text { M. Exp } \\
\mathbf{3}\end{array}$ & $\begin{array}{c}\text { M. Exp } \\
\mathbf{4}\end{array}$ & $\begin{array}{c}\text { M. Exp } \\
\mathbf{5}\end{array}$ & $\begin{array}{c}\text { M. Exp } \\
\mathbf{6}\end{array}$ \\
\hline B1 & L & L & ML & VL & ML & M \\
\hline B2 & L & ML & ML & L & M & ML \\
\hline B3 & VL & VL & VL & L & VL & ML \\
\hline B4 & VL & VL & L & VL & ML & ML \\
\hline B5 & VL & VL & VL & VL & ML & L \\
\hline B6 & VL & VL & VL & VL & VL & L \\
\hline \multicolumn{7}{|c|}{ L: Low, VL: Very low, ML: Medium low } \\
\hline
\end{tabular}

in the ET diagram was subsequently commenced. Sarıalioğlu et al. [8] calculated the probability of fire accidents in engine rooms of ships of 500 GRT and above as 7.401E-02. In this study, the said value was considered the occurrence probability of the IE. In this respect, using Equations (10-11), the probability values for each outcome in the ET diagram were calculated. The calculated failure probabilities pertaining to each barriers and outcomes are presented in Table 9.

Table 6. Similarity functions for B1

\begin{tabular}{|c|c|c|}
\hline No & Similarity function & Value \\
\hline 1 & S(E1\&E2) & 1.000 \\
\hline 2 & S(E1\&E3) & 0.850 \\
\hline 3 & S(E1\&E4) & 0.875 \\
\hline 4 & S(E1\&E5) & 0.850 \\
\hline 5 & S(E1\&E6) & 0.700 \\
\hline 6 & S(E2\&E3) & 0.850 \\
\hline 7 & S(E2\&E4) & 0.875 \\
\hline 8 & S(E2\&E5) & 0.850 \\
\hline 9 & S(E2\&E6) & 0.700 \\
\hline 10 & S(E3\&E4) & 0.725 \\
\hline 11 & S(E3\&E5) & 1.000 \\
\hline 12 & S(E3\&E6) & 0.850 \\
\hline 13 & S(E4\&E5) & 0.725 \\
\hline 14 & S(E4\&E6) & 0.575 \\
\hline 15 & S(E5\&E6) & 0.850 \\
\hline
\end{tabular}

Table 7. $A A, R A$ and $C C$ values of maritime experts for $B 1$

\begin{tabular}{|c|c|c|c|}
\hline M. Exp. No & AA & RA & CC \\
\hline 1 & 0.855 & 0.17 & 0.178 \\
\hline 2 & 0.855 & 0.17 & 0.178 \\
\hline 3 & 0.855 & 0.17 & 0.171 \\
\hline 4 & 0.755 & 0.15 & 0.161 \\
\hline 5 & 0.855 & 0.17 & 0.171 \\
\hline 6 & 0.735 & 0.15 & 0.140 \\
\hline AA: Average agreement, RA: Relative agreement, CC: Consensus coefficient \\
\hline
\end{tabular}

Table 8. Aggregated expert judgements and defuzzified failure possibilities for each barrier

\begin{tabular}{|c|c|c|c|c|c|}
\hline Barriers & \multicolumn{4}{|c|}{$\begin{array}{c}\text { Aggregated expert judgements on } \\
\text { failures }\end{array}$} & $\begin{array}{c}\text { Defuzzified } \\
\text { possibility }\end{array}$ \\
\hline B1 & 0.160 & 0.244 & 0.294 & 0.394 & 0.274 \\
\hline B2 & 0.198 & 0.298 & 0.348 & 0.448 & 0.323 \\
\hline B3 & 0.044 & 0.074 & 0.157 & 0.257 & 0.136 \\
\hline B4 & 0.079 & 0.126 & 0.209 & 0.309 & 0.183 \\
\hline B5 & 0.046 & 0.076 & 0.161 & 0.261 & 0.139 \\
\hline B6 & 0.014 & 0.028 & 0.114 & 0.214 & 0.095 \\
\hline
\end{tabular}


The final version of the ET diagram constructed in line with the data obtained from the analyses is shown in Figure 1.

\section{Results and Discussion}

Upon the conclusion of the risk analysis of the barriers designed in this study, it was found that the barrier with the highest probability of failure is the water mist system [P(B2): 1.14E-03]. In this respect, technical investigations should be performed on the factors that may cause the outage of water mist system, with the highest probability of failure, to better fight against potential ship engine room fires. It is known that fire detectors should operate synchronously and that fire detection and alarm systems should be active for the automatic activation of water mist system. In this respect, it should be considered that any failure or non-compliance related to these systems would

Table 9. Failure probabilities for each barriers and outcomes

\begin{tabular}{|c|c|c|c|}
\hline Barriers & $\begin{array}{c}\text { Probabilities } \\
\text { obtained from } \\
\text { possibilities }\end{array}$ & Outcomes & $\begin{array}{c}\text { Calculated } \\
\text { probabilities for } \\
\text { each outcomes }\end{array}$ \\
\hline B1 & $6.55 \mathrm{E}-04$ & 01 & $7.40 \mathrm{E}-02$ \\
\hline B2 & $1.14 \mathrm{E}-03$ & 02 & $4.84 \mathrm{E}-05$ \\
\hline B3 & $5.43 \mathrm{E}-05$ & 03 & $5.53 \mathrm{E}-08$ \\
\hline B4 & $1.63 \mathrm{E}-04$ & 04 & $3.00 \mathrm{E}-12$ \\
\hline B5 & $5.88 \mathrm{E}-05$ & 05 & $4.90 \mathrm{E}-16$ \\
\hline B6 & $1.35 \mathrm{E}-05$ & 06 & $2.88 \mathrm{E}-20$ \\
\hline & & 07 & $3.88 \mathrm{E}-25$ \\
\hline
\end{tabular}

prevent the automatic activation of the water mist systems. In addition, the manual operation procedures of the systems and regular repair and maintenance also require attention. Accordingly, the water mist system (B2), which was found to have the highest probability of failure, is also considered the most critical barrier.

It is remarkable that the barrier with the second highest probability of failure was found to be the fire detection and alarm system [P(B1): 6.55E-04]. Early detection of fires on ships is of critical significance $[1,58,59]$. In this respect, it was expected that these systems designed for the first stage of firefighting processes would be less likely to fail. The electronic and mechanical components of these system, in addition to the main and emergency power supplies that feed them, should be checked regularly to reduce the probability of failure of the system.

When the other barriers are considered, the probability of failure ranges from highest to lowest for the fire pump [P(B4):1.63E-04], emergency fire pump [P(B5): 5.88E-05], portable fire extinguishers [P(B3): 5.43E-05] and fixed $\mathrm{CO}_{2}$ fire extinguishing system [P(B6): 1.35E-05], respectively. When the probability of failure for all barriers is considered, it is relatively low. However, considering that engine rooms are of vital importance for ships [8], and that fire accidents have great potential to occur spontaneously, it is clearly of the utmost importance to conduct appropriate technical checks to further reduce the probability of failure of the barriers examined in this study.

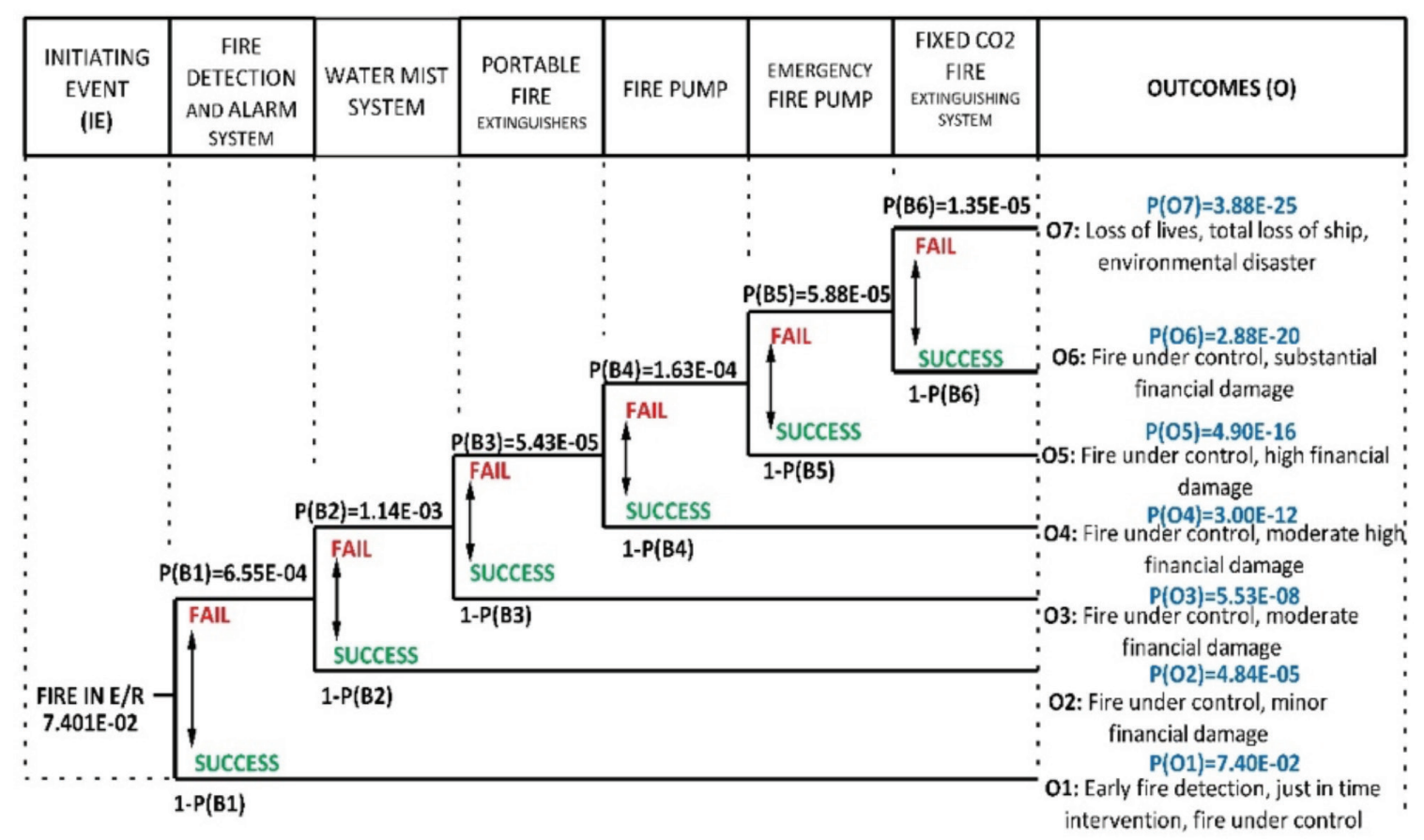

Figure 1. ET diagram for ship $(E / R)$ fires with probabilities and relevant outcomes 
All conducted repairs and maintenance, tests and surveys should comply with the provisions of SOLAS Chapter II-2/14.2.2 [12], and the minimum criteria defined in International Maritime Organization MSC.1/Circ.1432 [60], and MSC.1/Circ.1516 [61]. In addition, the repair and maintenance directives determined by the manufacturer of each individual system and the requirements of flag administrations should be fulfilled.

From a different perspective, it appears that several risks can be encountered in the event that designed barriers fail. These risks are defined as minor, moderate, moderately high, high and substantial in terms of financial damage, total loss of the ship, environmental disaster and loss of lives [62,63]. As can be seen, failures in the systems used in fighting engine room fires may have outcomes including loss of human lives in addition to financial and environmental losses. In this context, as the probability of failure of the systems designed for firefighting increases, it will be difficult to control the fire. This will increase the magnitude of the risk encountered.

\section{Conclusion}

A technical risk analysis of the fire detection and fire-fighting systems that can be used against potential fires in the engine rooms of ships of 500 GRT and above was conducted in this study. It is concluded that risks of various severity may be encountered in the event of the failure or outage of the systems designed for fighting fires. In this respect, repair, maintenance and testing are of great importance to ensure the efficient operation of the systems designed for fighting engine room fires. In addition, with the calculation of the probabilities of failure for each barrier and the outcomes to be encountered in different scenarios using the model constructed with fuzzy logic and ETA, a quantitative risk analysis was conducted. This has enabled better awareness of the different levels of risks that may be encountered as a result of ship engine room fire accidents. The water mist system has been determined as the most critical barrier as it has the highest probability of failure among the designed barriers. In this context, root causes that lead to malfunctions in systems with a higher probability of failure should be investigated [64]. In addition, the findings obtained in the study serve as a source for other risk analysis studies that can be done regarding fire extinguishing systems in the future.

It is believed that studying the effect of human factors on the failures of fire-fighting systems in ship engine rooms in future studies will further contribute to the minimisation of malfunctions or misuses of these systems. In this respect, ETA model can be designed from human errors at various levels, thus the probability of human- induced malfunctions in these systems can be measured and solutions can be offered for the elimination of these errors.

\section{Authorship Contributions}

Concept design: A.L. Tuncel, E. Akyuz, O. Arslan, Data Collection or Processing: A.L. Tuncel, E. Akyuz, O. Arslan, Analysis or Interpretation: A.L. Tuncel, E. Akyuz, Literature Review: A.L. Tuncel, Writing, Reviewing and Editing: A.L. Tuncel, O. Arslan.

Funding: The author(s) received no financial support for the research, authorship, and/or publication of this article.

\section{References}

[1] H.C. Kuo and, H.K. Chang, "A real-time shipboard fire-detection system based on grey-fuzzy algorithms," Fire Safety Journal, vol. 38, pp. 341-363, Jun 2003.

[2] A. Salem, "Fire engineering tools used in consequence analysis," Ships and Offshore Structures, vol. 5, pp. 155-187, 2010.

[3] T. Baalisampang, R. Abbassi, V. Garaniya, F. Khan, and M. Dadashzadeh, "Review and analysis of fire and explosion accidents in maritime transportation," Ocean Engineering, vol. 158, pp. 350-366, June 2018.

[4] R.M. Darbra, and J. Casal, "Historical analysis of accidents in seaports," Safety Science, vol. 42, pp. 85-98, Feb 2004.

[5] Ö. Uğurlu, U. Yıldırım, and E. Yüksekyıldız, "Marine accident analysis with GIS," Journal of Shipping and Ocean Engineering, vol. 3, pp. 21-29, Feb 2013.

[6] L. Wang, J. Wang, M. Shi, S. Fu, and M. Zhu, "Critical risk factors in ship fire accidents," Maritime Policy \& Management, pp. 1-19, Sep 2020.

[7] Det Norske Veritas, Engine room fires can be avoided. Veritasveien, Norway: Det Norske Veritas, 2020.

[8] S. Sarıalioğlu, Ö. Uğurlu, M. Aydın, B. Vardar, and J. Wang, "A hybrid model for human-factor analysis of engine-room fires on ships: HFACS-PV\&FFTA," Ocean Engineering, vol. 217, pp. 107992, Dec 2020.

[9] S. Su, and L. Wang, "Three dimensional reconstruction of the fire in a ship engine room with multilayer structures," Ocean Engineering, vol. 70, pp. 201-207, Sep 2013.

[10] R. Bellas, M.A. Gómez, A. González-Gil, J. Porteiro, and J. L. Míguez, "Assessment of the fire dynamics simulator for modeling fire suppression in engine rooms of ships with low-pressure water mist," Fire Technology, vol. 56, pp. 1315-1352, Nov 2019.

[11] R. Puisa, S. Williams, and D. Vassalos, "Towards an explanation of why onboard fires happen: the case of an engine room fire on the cruise ship 'Le Boreal',' Applied Ocean Research, vol. 88, pp. 223-232, Jul 2019.

[12] International Maritime Organization, SOLAS Consolidated Edition 2020. London: International Maritime Organization Publishing, 2020.

[13] International Maritime Organization, FSS Code: International code for fire safety systems. London: International Maritime Organization Publishing, 2015. 
[14] Ö. Uğurlu, "Analysis of fire and explosion accidents occurring in tankers transporting hazardous cargoes," International Journal of Industrial Ergonimics, vol. 55, pp. 1-11, Sep 2016.

[15] Y. Guan, J. Zhao, T. Shi, and P. Zhu, "Fault tree analysis of fire and explosion accidents for dual fuel (diesel/natural gas) ship engine rooms," Journal of Marine Science and Application, vol. 15, pp. 331-335, Jul 2016.

[16] H. Karahalios, "Effect of human behaviour in shipboard firefighting decisions: the case of fire in engine rooms," Journal of Contingencies and Crisis Management, vol. 25, pp. 256-268, Jan 2017.

[17] J.R. Harrald, et al. "Using system simulation to model the impact of human error in a maritime system," Safety Science, vol. 30, pp. 235-247, Dec 1998.

[18] A. Toffoli, J.M. Lefevre, E. Bitner-Gregersen, and J. Monbaliu, "Towards the identification of warning criteria: analysis of a ship accident database," Applied Ocean Research, vol. 27, pp. 281-291, Dec 2005.

[19] P. Antao and C.G. Soares, "Fault-tree models of accident scenarios of RoPax vessels," International Journal of Automation and Computing, vol. 2, pp. 107-116, 2006.

[20] O. Arslan, and I.D. Er, "A SWOT analysis for successful bridge team organization and safer marine operations.," Process Safety Progress, vol. 27, pp. 21-28, Jul 2007.

[21] J.U. Schröder-Hinrichs, M. Baldauf, K.T. Ghirxi, "Accident investigation reporting deficiencies related to organizational factors in machinery space fires and explosions," Accident Analysis \& Prevention, vol. 43, pp. 1187-1196, May 2011.

[22] O. Soner, U. Asan, and M. Celik, "Use of HFACS-FCM in fire prevention modelling on board ships," Safety Science, vol. 77, pp. 25-41, Aug 2015.

[23] P.A. Sarvari, E. Çevikcan, M. Çelik, and A. Üstündağ, "A simulation aided methodology suggestion for managing emergency evacuation operation under engine room sourced fire conditions," Journal of ETA Maritime Science, vol. 5, pp. 362-385, Oct 2017.

[24] B.O. Tac, E. Akyuz, and M. Celik, "Analysis of performance influence factors on shipboard drills to improve ship emergency preparedness at sea," International Journal of Shipping and Transport Logistics, vol. 12, pp. 92-116, 2020.

[25] R. Tao, H.X. Ren, and X.Q. Peng, "Ship fire-fighting training system based on virtual reality technique," in Proceedings of 17th Asia Simulation Conference, part 2, M.S.M. Ali, H. Wahid, N.A.M. Subha, S. Sahlan, M.A.M. Yunus, A.R. Wahap, Eds. Singapore: Springer, 2020, pp. 249-260.

[26] J. McNay, R. Puisa, and D. Vassalos, "Analysis of effectiveness of fire safety in machinery spaces. Fire Safety Journal, vol. 108, pp. 102859, Sep 2019.

[27] Y. Jin, and B.S. Jang, "Probabilistic fire risk analysis and structural safety assessment of FPSO topside module," Ocean Engineering, vol. 104, pp. 725-737, Aug 2015.

[28] R. Yang, F. Khan, M. Yang, D. Kong, and C. Xu, "A numerical fire simulation approach for effectiveness analysis of fire safety measures in floating liquefied natural gas facilities," Ocean Engineering, vol. 157, pp. 219-233, Jun 2018.

[29] L.A. Zadeh, "Fuzzy sets," Information and Control, vol. 8, pp. 338353, Jun 1965.
[30] F. Castiglia, and M. Giardina, "Analysis of operator human errors in hydrogen refuelling stations: comparison between human rate assessment techniques," International Journal of Hydrogen Energy, vol. 38, pp. 1166-1176, Jan 2013.

[31] A. Barua, L.S. Mudunuri, and 0. Kosheleva, "Why trapezoidal and triangular membership functions work so well: towards a theoretical explanation," Journal of Uncertain Systems, vol. 8, Oct 2013.

[32] J. Wang, et al. "Use of advances in technology for maritime risk assessment," Risk Analysis, vol. 24, pp. 1041-1063, Sep 2004.

[33] P. Badida, Y. Balasubramaniam, and J. Jayaprakash, "Risk evaluation of oil and natural gas pipelines due to natural hazards using fuzzy fault tree analysis," Journal of Natural Gas Science and Engineering, vol. 66, pp. 284-292, Jun 2019.

[34] J.X. Wang, and M.L. Roush, What every engineer should know about risk engineering and management. New York: CRC Press, 2000.

[35] N. Ramzali, M.R.M. Lavasani, and J. Ghodousi, "Safety barriers analysis of offshore drilling system by employing fuzzy event tree analysis," Safety Science, vol. 78, pp. 49-59, Oct 2015.

[36] R. Ferdous, F. Khan, R. Sadiq, P. Amyotte, and B. Veitch, "Handling data uncertainties in event tree analysis," Process Safety and Environmental Protection, vol. 87, pp. 283-292, Sep 2009.

[37] T. Aven, Reliability and risk analysis. London and New York: Elsevier Applied Science, 1992.

[38] S. Mannan. Lees' Loss prevention in the process industries: Hazard identification, assessment and control. 4th ed. Vol. 1, Oxford: Elsevier, 2012.

[39] S. Fu, X. Yan, D. Zhang, C. Li, and E. Zio, "Framework for the quantitative assessment of the risk of leakage from LNG-fueled vessels by an event tree-CFD," Journal of Loss Prevention in the Process Industries, vol. 43, pp. 42-52, Sep 2016.

[40] A. Raiyan, S. Das, and M. R. Islam, "Event tree analysis of marine accidents in Bangladesh," Procedia Engineering, vol. 194, pp. 276-283, 2017.

[41] N. J. Duijm, "Safety-barrier diagrams as a safety management tool," Reliability Engineering \& System Safety, vol. 94, pp. 332341, Feb 2009.

[42] S. Sklet, "Safety barriers: definition, classification, and performance," Journal of Loss Prevention in the Process Industries, vol. 19, pp. 494-506, Sep 2006.

[43] M. Rausand, Risk assessment: theory, methods and applications. Hoboken, New Jersey: John Wiley \& Sons, 2013.

[44] A.D. Livingston, G. Jackson, and K. Priestley, "Root causes analysis: Literature review," HSE Contract Research Report 325/2001, WS Atkins Consultants Ltd for the Health and Safety Executive, Norwich, United Kingdom, 2001.

[45] S.M. Lavasani, N. Ramzali, F. Sabzalipour, and E. Akyuz, "Utilisation of Fuzzy Fault Tree Analysis (FFTA) for quantified risk analysis of leakage in abandoned oil and natural-gas wells," Ocean Engineering, vol. 108, pp. 729-737, Nov 2015.

[46] D. Yuhua, and Y. Datao, "Estimation of failure probability of oil and gas transmission pipelines by fuzzy fault tree analysis," Journal of Loss Prevention in the Process Industries, vol. 18, pp. 83-88, Mar 2005.

[47] E. Akyuz, O. Arslan, and O. Turan, "Application of fuzzy logic to fault tree and event tree analysis of the risk for cargo liquefaction 
on board ship," Applied Ocean Research, vol. 101, pp. 102238, Aug 2020.

[48] H.M. Hsu, and C.T. Chen, "Aggregation of fuzzy opinions under group decision making," Fuzzy Sets and Systems, vol. 79, pp. 279285, May 1996.

[49] H.T. Nguyen and N.R. Prasad, Eds., Fuzzy modeling and control: Selected works of M. Sugeno. Boca Raton, Florida: CRC Press, 1999.

[50] T. Onisawa, "An approach to human reliability in man-machine systems using error possibility," Fuzzy Sets and Systems, vol. 27, pp. 87-103, Aug 1998.

[51] A.D. Swain, and H.E. Guttmann, "Handbook of human-reliability analysis with emphasis on nuclear power plant applications," Final Report (NUREG/CR-1278), United States, 1983.

[52] S. Mineo, G. Pappalardo, A. D’Urso, and D. Calcaterra, "Event tree analysis for rockfall risk assessment along a strategic mountainous transportation route," Environmental Earth Science, vol. 76, pp. 620, Sep 2017.

[53] S. Zhang, "Fire protection onboard: enhance fire safety by design," Master dissertion, (MSc Thesis). World Maritime University, Malmö, Sweden, 2000.

[54] A.C. Kuzu, E. Akyuz, and O. Arslan, "Application of fuzzy fault tree analysis (FFTA) to maritime industry: a risk analysing of ship mooring operation," Ocean Engineering, vol. 179, pp. 128-134, May 2019.

[55] B. Sahin, "Consistency control and expert consistency prioritization for FFTA by using extent analysis method of trapezoidal FAHP," Applied Soft Computing, vol. 56, pp. 46-54, Jul 2017.

[56] S.J. Chen, and C. L. Hwang, (1992). "Fuzzy Multiple Attribute Decision Making Methods," in Fuzzy Multiple Attribute Decision Making: Methods and Applications Berlin, Heidelberg: Springer-Verlag, 1992, pp. 289-486.
[57] Y.E. Senol, Y.V. Aydogdu, B. Sahin, and I. Kilic, "Fault tree analysis of chemical cargo contamination by using fuzzy approach," Expert Systems with Applications, vol. 42, pp. 5232-5244, Jul 2015.

[58] S.J. Wang, D.L. Jeng, and M.T. Tsai, "Early fire detection method in video for vessels," Journal of Systems and Software, vol. 82, pp. 656-667, Apr 2009.

[59] H. Sim, W.J. Ha, and Y.S. Park, "A basic study on standardization of fire-fighting drill scenarios on board," Journal of International Maritime Safety Environmental Affairs and Shipping, vol. 3, pp. 28-35, Dec 2019.

[60] International Maritime Organization, Revised guidelines for the maintenance and inspection of fire protection systems and appliances (MSC.1/Circ.1432). London: International Maritime Organization, 2012.

[61] International Maritime Organization, Amendments to the revised guidelines for the maintenance and inspection of fire protection systems and appliances (MSC.1/Circ.1516). London: International Maritime Organization, 2015.

[62] E. Akyuz, E. Celik, and M. Celik, "A practical application of human reliability assessment for operating procedures of the emergency fire pump at ship," Ships and Offshore Structures, vol. 13, pp. 208-216, 2018.

[63] E. Akyuz, and E. Celik, "The role of human factor in maritime environment risk assessment: a practical application on Ballast Water Treatment (BWT) system in ship," Human and Ecological Risk Assessment: An International Journal, vol. 24, pp. 653-666, 2018.

[64] M. Aydin, E. Akyuz, O. Turan, and O. Arslan, "Validation of risk analysis for ship collision in narrow waters by using fuzzy Bayesian networks approach," Ocean Engineering, vol. 231, pp. 108973, Jul 2021. 